\title{
Nuclear Breast Imaging: Clinical Results and Future Directions
}

\author{
Wendie A. Berg \\ Department of Radiology, University of Pittsburgh School of Medicine, Magee-Womens Hospital of UPMC, Pittsburgh, Pennsylvania
}

\begin{abstract}
Interest in nuclear breast imaging is increasing because of technical improvements in dedicated devices that allow the use of relatively low doses of radiotracers with high sensitivity for even small breast cancers. For women with newly diagnosed cancer, primary chemotherapy is often recommended, and improved methods of assessing treatment response are of interest. With widespread breast density notification, functional rather than anatomic methods of screening are of increasing interest as well. For a cancer imaging technology to be adopted, several criteria must be met that will be discussed: evidence of clinical benefit with minimal harm, standardized interpretive criteria, direct biopsy guidance, and acceptable cost-effectiveness.
\end{abstract}

Key Words: breast cancer; positron emission mammography; molecular breast imaging; breast PET; breast MRI; screening

J Nucl Med 2016; 57:46S-52S

DOI: 10.2967/jnumed.115.157891

$\mathbf{T}$

wo radiotracers have been used widely to depict breast cancer: the $\gamma$-emitting ${ }^{99 \mathrm{~m}} \mathrm{Tc}$-sestamibi ( ${ }^{99 \mathrm{~m}} \mathrm{Tc}$-methoxyisobutylisonitrile), $140 \mathrm{keV}$, half-life of $6 \mathrm{~h}$, originally developed as a myocardial perfusion agent; and the positron-emitting glucose analog ${ }^{18} \mathrm{~F}-\mathrm{FDG}, 511$ $\mathrm{keV}$, half-life of $2 \mathrm{~h}$. Standard lead shielding as is used in a mammography suite is sufficient when using ${ }^{99} \mathrm{~m}$ Tc-sestamibi. Using ${ }^{18} \mathrm{~F}$ FDG requires much more extensive shielding and may not be feasible because of workspaces above or below the planned unit. State licensing requirements for nuclear medicine must be considered; typically, a hot lab with oversight by a trained nuclear medicine technologist and a physicist is required (1).

Both ${ }^{99 m}$ Tc-sestamibi and ${ }^{18} \mathrm{~F}-\mathrm{FDG}$ were initially studied for breast cancer using whole-body scanners. Low sensitivity to invasive cancers smaller than $1 \mathrm{~cm}$ was observed with whole-body $\gamma$-camera imaging in a prospective multicenter series at $48.2 \%$, compared with $74.2 \%$ for larger tumors (2); detection of small cancers, particularly small invasive cancers, is a major goal of breast imaging. Similar results were observed with whole-body PET, with sensitivity to invasive tumors $2 \mathrm{~cm}$ or smaller of only 30 of $44(68 \%)$ compared with 57 of 62 (92\%) for larger cancers (3).

Dedicated breast $\gamma$-camera imaging can be performed with singledetector scintillating-crystal systems such as breast-specific $\gamma$-imaging (BSGI) (Dilon Technologies) with a $20 \times 15 \mathrm{~cm}$ field of view, 3.3-mm

Received Aug. 25, 2015; revision accepted Oct. 28, 2015.

For correspondence or reprints contact: Wendie A. Berg, Department of Radiology, Magee-Womens Hospital, 300 Halket St., Pittsburgh, PA 15213. E-mail: wendieberg@gmail.com

COPYRIGHT (C) 2016 by the Society of Nuclear Medicine and Molecular Imaging, Inc. pixel size; or using dual-head cadmium-zinc-telluride detector systems, often referred to as molecular breast imaging (MBI) (GE Healthcare, with a $24 \times 16 \mathrm{~cm}$ field of view and $2.5-\mathrm{mm}$ pixel size; or Gamma Medica, Inc., with a $20 \times 16 \mathrm{~cm}$ field of view and $1.6 \mathrm{~mm}$ pixel size). Both approaches use positioning similar to that of mammography, with the breast gently stabilized between a compression paddle and the detector (BSGI) or between 2 detectors (MBI). It is important to include mammographic technologists in the positioning of the patients, at least for a minimum number of cases (e.g., 25), to ensure full inclusion of posterior tissues for both a craniocaudal and a mediolateral oblique (MLO) acquisition. Particularly with the dualhead systems, it can be difficult to prevent skin folds or to ensure that the nipple is in profile because the opaque detectors block direct visualization of the breast during positioning.

Typically, imaging begins within 5 min after intravenous radiotracer injection and includes 10-min acquisitions in both craniocaudal and MLO projections of each breast, for a total minimum of $40 \mathrm{~min}$ to examine both breasts. Additional views such as a laterally exaggerated craniocaudal view or axillary tail view may be needed to fully include all breast tissue, and even then the extreme posterior tissues are difficult to fully include when positioning the breast between 2 rather bulky detectors on MBI or positron emission mammography (PEM) (CMR Naviscan). In a series of 149 invasive cancers imaged by BSGI (4), all cancers $8 \mathrm{~mm}$ or larger were visualized, as were all cancers grade 2 or higher; only 3 of 6 grade 1 cancers $7 \mathrm{~mm}$ or smaller were seen. In prototype studies of lesions imaged before biopsy using a single- versus dual-head MBI system (5), only 2 of 7 (29\%) cancers $5 \mathrm{~mm}$ or smaller and 24 of $28(86 \%)$ of those 6-10 $\mathrm{mm}$ were detected on the single-head system compared with 11 of $16(69 \%) 5 \mathrm{~mm}$ or smaller and 41 of $45(91 \%) 6-10 \mathrm{~mm}$ on the dual-head system. Dual-head systems are generally now used for clinical MBI. In a more recent series using MBI (6), among 357 invasive cancers for which pathology size was available, $310(87 \%)$ were seen; sensitivity was reduced for smaller tumors, with 45 of 63 (71\%) cancers $5 \mathrm{~mm}$ or smaller seen, 64 of $84(76 \%)$ of those 6$10 \mathrm{~mm}, 75$ of $81(93 \%)$ of those $11-15 \mathrm{~mm}, 43$ of $45(96 \%)$ of those 16-20 mm, and 83 of $84(99 \%)$ of those larger than $2 \mathrm{~cm}$ identified on MBI (Amy L. Conners, personal communication, August 2015; $P<0.0001$ by $\chi^{2}$ test). Of 49 MBI-occult cancers, 8 (16\%) were thought to have been outside the field of view (which corresponded to 8 of $360,2.2 \%$ of all tumor foci) (6). Of note, ${ }^{99 \mathrm{~m} T c-s e s t a m i b i}$ was first used as a cardiac radiotracer, and it is possible to perform dedicated breast $\gamma$-camera imaging after cardiac imaging using the same dose of radiotracer (7).

Several dedicated breast PET devices have been developed; and again, imaging can be performed after PET/CT or PET/MRI using the same radiotracer dose, although insurance reimbursement may be denied for the breast PET in that circumstance. The first PEM system (CMR Naviscan) uses positioning similar to that of 
mammography, with the breast gently stabilized between a transparent compression paddle and the detector, and 10-min craniocaudal and MLO acquisitions. In direct comparison studies, PEM has shown greater sensitivity to small cancers than whole-body PET or PET/CT, although only 10 of $14(71 \%)$ index cancers $6-10 \mathrm{~mm}$ in size and 5 of $12(42 \%) 5 \mathrm{~mm}$ or smaller were seen on PEM in one series (8), as were 11 of $15(73 \%)$ cancers $1 \mathrm{~cm}$ or smaller in another series (9). Despite direct involvement of mammography technologists in positioning or at least the initial training of nuclear medicine technologists in positioning at least the first 25 patients per site, inadequate positioning was prospectively reported in 36 of 388 (9.3\%) participants in a multicenter PEM trial; another $11(2.8 \%)$ participants had large breasts, requiring tiled images to include all breast tissue (10). In part because of the coincidence requirement for counting positron emissions (at $180^{\circ}$ from each other), approximately $1 \mathrm{~cm}$ of tissue at the extreme posterior of the breast is not well evaluated on PEM.

Dedicated prone breast PET systems, which should improve visualization of posterior tissues, have also been developed: Mammi-PEM (Oncovision; Gem Imaging SA), Clear PEM (Crystal Clear Collaboration; CERN), and O-scanner (Shimadzu Medical Systems), as well as a C-scanner in which the seated patient leans into a C-shaped detector system (Shimadzu). With ${ }^{18}$ F-FDG-based imaging, the radiotracer must circulate for at least an hour before imaging is started, and longer circulation times of up to $2 \mathrm{~h}$ seem to improve lesion-to-background uptake.

Both ${ }^{99 m}$ Tc-sestamibi- and ${ }^{18} \mathrm{~F}-\mathrm{FDG}$-based breast imaging benefit from the patient fasting, with greater radiotracer uptake by the breast tissue in a fasting state $(11)$. For ${ }^{18} \mathrm{~F}-\mathrm{FDG}$, a minimum of a 4-h and preferably a 6-h fast is recommended. The patient should be kept resting and warm to minimize muscle uptake of either radiotracer (11). The injection site (typically the antecubital fossa) can be imaged to ensure lack of infiltration or muscle uptake.

For all medical imaging, it is important to minimize the dose of ionizing radiation while still providing appropriate diagnostic information. This is particularly true when imaging younger individuals who have at least a 10 - to 20-y life expectancy during which radiation-induced cancers could be observed. Women who are pregnant or lactating should not be imaged with nuclear breast techniques. Most published articles about BSGI reported injected doses of 555-1,110 MBq (15-30 mCi). With dual-head cadmium-zinc-telluride detector systems and optimized collimator and energy windows, an injected dose averaging $300 \mathrm{MBq}(8.1 \mathrm{mCi})$ has been used while maintaining performance characteristics (12). Unlike mammography, radiation exposure during nuclear breast imaging is to the whole body, with the greatest accumulation of ${ }^{99} \mathrm{~m}$ Tc-sestamibi seen in the colon, kidneys, bladder, and gallbladder. The effective dose from a $300-\mathrm{MBq}(8.1-\mathrm{mCi})$ injection, considering the radiation risk to each organ, is $2.4 \mathrm{mSv}$, compared with about $0.4 \mathrm{mSv}$ for mammography (13). Use of a $150-\mathrm{MBq}$ (4-mCi) dose of ${ }^{99 \mathrm{~m}} \mathrm{Tc}$-sestamibi is under study and may be possible with optimal patient preparation (11) and the use of appropriate syringes that minimize the adherence of ${ }^{99 \mathrm{~m} T c-s e s t a m i b i}(14)$.

The published literature on PEM has typically used an ${ }^{18} \mathrm{~F}-\mathrm{FDG}$ dose of $370 \mathrm{MBq}(10 \mathrm{mCi})$ for an effective dose of $6.2-7.1 \mathrm{mSv}$ (15), with the highest dose to the bladder.

Importantly, such radiation exposures from nuclear breast imaging are at or below the 3- to $10-\mathrm{mSv}$ background radiation dose from living on Earth for $1 \mathrm{y}$. According to the American Association of Physicists in Medicine, the risks of medical imaging at effective doses of less than $50 \mathrm{mSv}$ for single procedures, or $100 \mathrm{mSv}$ for multiple procedures over short periods, are too low to be detectable and may be nonexistent (16).

\section{THE EVIDENCE}

Many applications of nuclear breast imaging are for the same indications for which contrast-enhanced breast MRI would be used. Diagnostic breast imaging can include problem solving when vague abnormalities persist after additional mammographic views and ultrasound; but with current ultrasound equipment and tomosynthesis, it is rare to require further diagnostic imaging. Sensitivity is at least as high as ultrasound with BSGI, but specificity is higher with BSGI $(17,18)$. In patients presenting with cancer of unknown primary cause (typically, a metastatic axillary node consistent with breast cancer), both ${ }^{99} \mathrm{~m}$ Tc-sestamibi- and ${ }^{18} \mathrm{~F}-\mathrm{FDG}$-based imaging can identify the underlying breast cancer (Fig. 1); however, no series have been published on this issue. Although papillomas may show abnormal uptake of either radiotracer, MBI was negative in all 14 patients with bloody nipple discharge in one series, including 2 patients with papillomas and one with invasive cancer found 17 mo later (19).
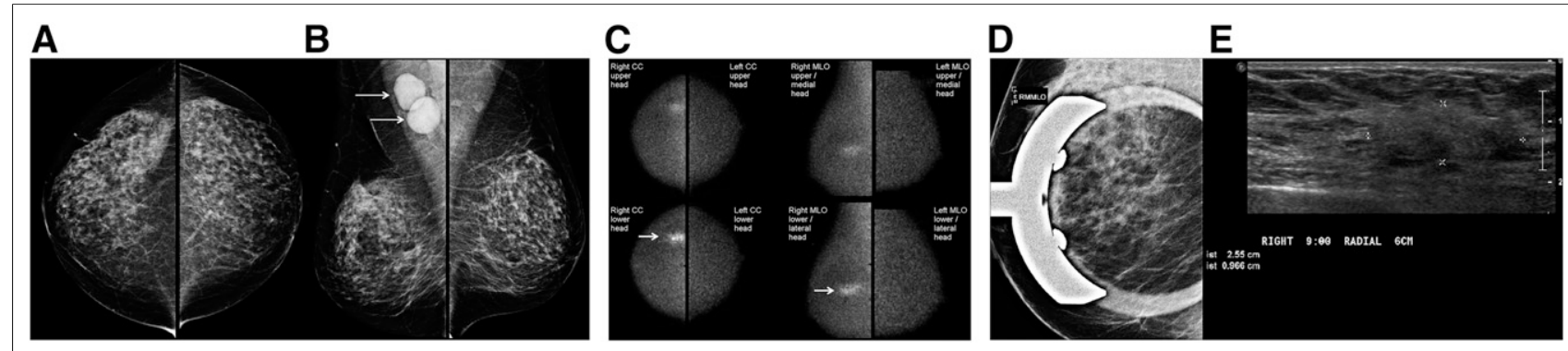

FIGURE 1. Use of MBI to identify cancer of unknown primary cause. (A) This 58 -y-old woman presented for screening mammography. Craniocaudal views show heterogeneously dense parenchyma and no suspicious findings. (B) On MLO views, large, dense, suspicious nodes are seen in right axilla (arrows), without suspicious findings in either breast. Ultrasound-guided core biopsy of one node showed invasive carcinoma consistent with breast primary. (C) Craniocaudal and MLO 10-min views from dual-head direct-conversion MBI obtained after intravenous injection of $740 \mathrm{MBq}$ (20 mCi) of 99mTc-sestamibi show intense segmental uptake spanning $3.4 \mathrm{~cm}$ (arrows) in 9-o'clock position in right breast $6 \mathrm{~cm}$ from nipple, which is suggestive of cancer. Metastatic nodes were not included on these images. Left breast appears normal. (D) Spot magnification right MLO mammogram over area of 99mTc-sestamibi uptake is unremarkable. (E) Targeted ultrasound demonstrates vague mixed-echogenicity irregular 2.6-cm mass (denoted by calipers), corresponding to abnormality on MBI. Ultrasound-guided core biopsy showed grade 1 ILC that was estrogen receptor-positive, progesterone receptor-positive, and HER2/neu (ERB-B2)-negative. Patient had primary chemotherapy with little response, with residual disease at surgery measuring $2.2 \mathrm{~cm}$. CC = craniocaudal. (Courtesy of Carrie Hruska, PhD, and Amy Conners, MD, Mayo Clinic.) 


\section{EXTENT OF DISEASE}

MRI has been widely studied for assessing extent of disease in women with newly diagnosed cancer. Metaanalyses show additional ipsilateral mammographically occult disease in $16 \%$ of women, with a positive predictive value (PPV) of additional MRI findings of $66 \%$ (20); and in the contralateral breast, occult disease is found in $4 \%$ of women on average, with a PPV of MRI findings of $48 \%$ (21).

A few retrospective studies have evaluated the use of ${ }^{99 \mathrm{~m}} \mathrm{Tc}-$ sestamibi-based breast imaging to assess disease extent. In one series (22), 9 of 159 (6\%) women had additional unsuspected ipsilateral foci, and 5 (3\%) had contralateral foci seen on BSGI, with a PPV of suggestive findings on BSGI of 14 of 40 (35\%). The PPV of additional suggestive findings was 15 of $25(60 \%)$ in a series of 138 women studied by Zhou et al. (23), and 7 of 18 (39\%) (including one ductal carcinoma in situ [DCIS] excised) in a series of 82 women reported by Killelea et al. (24). The PPV of additional suspicious findings of only $35 \%-60 \%$ underscores the importance of percutaneous biopsy of additional suspicious findings before converting a patient to mastectomy.

In a series of 66 women who underwent BSGI and MRI (25), specificity was higher for BSGI, at $90 \%$, than for MRI, at $39 \%(P<$ $0.0001)$. In a series of 118 women anticipating breast-conserving therapy, $14(11.9 \%)$ were appropriately converted to mastectomy on the basis of BSGI; another 15 of the $104(14.4 \%)$ remaining women thought to be candidates for breast-conserving therapy required mastectomy (underestimated extent on BSGI), with more than half of those being underestimated because of a greater extent of DCIS than seen on BSGI (26). In a series of 286 patients with 390 invasive tumor foci imaged by MBI (6), $341(87.4 \%)$ foci were seen on MBI, although ascertainment of missed cancers depends on detailed pathologic analysis exceeding that in routine practice.

PEM has been compared with MRI for assessing local disease extent in a prospective multicenter series of 388 women with newly diagnosed breast cancer $(10,27)$. PEM showed comparable but complementary sensitivity in the ipsilateral breast and higher specificity than MRI, with a PPV of additional suspicious ipsilateral findings on PEM of 47 of $71(66 \%)$ compared with 61 of $116(53 \%)$ for MRI $(P=0.016)$. In the same series of 388 women, 15 (3.9\%) had contralateral cancer identified after study entry, with 14 of 15 (93\%) seen on MRI, only 3 of 15 (20\%) prospectively seen on PEM, and only 11 of $15(73 \%)$ visible even in retrospect on PEM. The PPV of PEMprompted contralateral biopsies ( 3 of 14, or 21\%) was not different from that of MRI (15 of 54, or $28 \%)(P=0.58)(27)$.

The dilemma with imaging the extent of disease is that, despite extensive study, MRI generally has not been shown to reduce the risk of local or distant recurrence (28), and no studies have been conducted to show such an impact with nuclear breast imaging, but similar issues likely apply. Further studies with molecular subtypes may prove more fruitful and are ongoing. In breast cancers lacking estrogen, progesterone, and HER2-neu (ERB-B2) receptors-that is, triple negative-lack of exposure to pretreatment breast MRI has been shown to independently correlate with an increased risk of recurrence at a median follow-up of $6.1 \mathrm{y}$, with a hazard ratio of 2.66 (95\% confidence interval, 1.49-4.75), comparable in magnitude to dense breasts and lymphovascular invasion (29). Unlike series across all tumor types $(30,31)$, MRI did not increase the rate of mastectomy in women with triple-negative disease (29). Reexcision rates are generally not reduced by preoperative MRI $(31,32)$, although MRI has been shown to be beneficial in presurgical planning for invasive lobular carcinoma (ILC) $(33,34)$. Size of unifocal carcinoma is better assessed by imaging than is detailed mapping of multiple foci of disease (10), in which it can be difficult to translate imaging findings to intraoperative positioning and excision.

Neither ${ }^{99 \mathrm{~m}}$ Tc-sestamibi- nor ${ }^{18} \mathrm{~F}$-FDG-based imaging is reliable at identifying metastatic axillary adenopathy; only 10 of 78 (13\%) metastatic axillae were prospectively identified by PEM (10). The axilla cannot be reliably included on devices that use positioning similar to that of mammography. Normal nodes can show mild radiotracer accumulation, but small metastatic deposits may not. Extravasation of radiotracer during injection of ${ }^{99} \mathrm{~m} \mathrm{Tc}$-sestamibi can produce abnormal uptake in ipsilateral nodes, which is more intense than that due to metastasis (35).

The use of nuclear medicine methods to assess residual disease before reexcision in patients with initial breast-conserving surgery for cancer with positive margins has not been studied. ${ }^{18} \mathrm{~F}-\mathrm{FDG}$ uptake is increased by prior biopsy or surgery; thus, the area near the surgical site cannot be acutely evaluated with breast PET. Scars lacking inflammation from fat necrosis typically do not show uptake after about $2 \mathrm{y}$, and PET can be used to help distinguish scarring from recurrence (36).

\section{SCREENING}

The perfect screening test would detect clinically important breast cancers only when they can be easily treated, would not detect any other lesions or induce any malignancies, and would be widely available and well tolerated. Because mammography is the only screening method that has been studied in randomized controlled trials and shown to reduce mortality from breast cancer (37), any other methods of screening are still viewed as supplements to mammography. Annual screening with MRI is recommended for women at a high risk for breast cancer because of known or suspected pathogenic mutations in the BRCA1 or BRAC2 gene or other less common mutations (for which screening may begin at age 25-30 y); because of a history of chest radiation therapy at least 8 years earlier and before age $30 \mathrm{y}$; or, based on models that predict the risk of being a mutation carrier, because of a strong family history that carries at least a $20 \%-$ $25 \%$ lifetime risk of breast cancer (38). Dense breast tissue reduces mammographic sensitivity and specificity $(39,40)$ but does not reduce the sensitivity of ${ }^{99 \mathrm{~m}} \mathrm{Tc}$-sestamibi-based imaging (41). Most women in the United States (42) are being notified of their breast density: there is increasing discussion of supplemental screening in women with dense breasts (heterogeneously dense or extremely dense by BI-RADS [Breast Imaging Reporting and Data System] categories) (43).

${ }^{99 \mathrm{~m}} \mathrm{Tc}$-sestamibi-based breast imaging using BSGI has been explored for screening high-risk women who cannot tolerate MRI (44), although radiation exposure is of greater concern in young women and in BRCA1-, BRCA2-, or TP53-mutation carriers with impaired DNA repair. More extensively, a Mayo Clinic group has explored using ${ }^{99 m}$ Tc-sestamibi and dual-head cameras for supplemental screening in women with dense breasts $(45,46)$. As shown in Table 1 , the sensitivity and specificity of MBI compare quite favorably with other methods of supplemental screening. In an analysis of induced costs from such screening, the Mayo Clinic group concluded that the cost per cancer diagnosis for mammography plus MBI was actually lower than that of mammography alone (47). As a result of these studies, across its multistate system, the Mayo Clinic is now offering biennial screening with MBI to women with dense breasts to supplement annual mammography or tomosynthesis. Monitoring outcomes will be important. 
TABLE 1

Summary of Prevalence Screening, Cancer Detection, and Recall Rates by Modality After Digital Mammography

\begin{tabular}{|c|c|c|c|c|}
\hline $\begin{array}{l}\text { If } 1,000 \text { women } \\
\text { with dense breasts } \\
\text { are screened with... }\end{array}$ & $\begin{array}{l}\text { Number of additional } \\
\text { women found to have } \\
\text { cancer will be... }\end{array}$ & Using... & $\begin{array}{l}\text { At a relative } \\
\text { cost of...* }\end{array}$ & $\begin{array}{l}\text { And number of women } \\
\text { recalled for additional } \\
\text { testing will be... }\end{array}$ \\
\hline $\mathrm{MBI}$ & 8 & $\begin{array}{l}\text { Intravenous radioactive } \\
\text { agent }\end{array}$ & $\$ 400$ & Another 65 \\
\hline Tomosynthesis & $1-2$ & Ionizing radiation & $\$ 60$ & 18-30 fewer \\
\hline Ultrasound & $2-4$ & Sound waves & $\$ 165$ & Another 130 \\
\hline Contrast-enhanced MRI & 10 & $\begin{array}{l}\text { Magnetic field and intravenous } \\
\text { contrast material }\end{array}$ & $\$ 1,000$ & Another 90 \\
\hline
\end{tabular}

${ }^{*}$ Based on estimated average reimbursement as of August 2015.

Data are from Wendie A. Berg, MD, PhD; adapted from http://densebreast-info.org/Technology.aspx. Accessed October $12,2015$.

In addition to concerns about radiation exposure, patient preparation, licensing requirements, and patient throughput when a minimum of $40 \mathrm{~min}$ is required for the examination, there are other current limitations to nuclear medicine approaches to screening. The cancer detection rates from annual or biennial ${ }^{99 \mathrm{~m}} \mathrm{Tc}$-sestamibi-based screening have not been reported; and there is no method of direct biopsy for findings detected on MBI, although stereotactic BSGI-guided biopsy is available. The logistics and radiation dose incurred when using ${ }^{18} \mathrm{~F}-$ FDG preclude interest in breast PET for screening, although direct PEM-guided biopsy is readily performed (48).

\section{STANDARDIZED INTERPRETIVE CRITERIA AND QUANTIFICATION}

Lexicons to describe findings on $\gamma$-camera imaging (49) and on breast PET (50) have been developed, and both have shown ease of use and substantial reproducibility for most terms $(51,52)$. Whenever possible, the same terminology and format used in BIRADS for mammography (43), ultrasound (53), and MRI (54) have been adopted for nuclear breast imaging, with assessments being scored on a 5-point scale: 1 , negative; 2 , benign; 3 , probably benign; 4, suspicious; and 5 , highly suggestive of malignancy. $\mathrm{Nu}-$ clear breast imaging must be interpreted together with current mammography, any other prior breast imaging, and a thorough biopsy history; as a result, interpretation should be performed by, or at least include, radiologists who meet experience requirements for breast imaging. Indeed, in the multicenter PEM-MRI trial (10), 7 of 82 (9\%) breasts with additional tumor foci were identified only on review of mammography and ultrasound. Any focal radiotracer uptake should be viewed with suspicion except when there is a known benign correlate such as a mammographically stable intramammary or axillary lymph node; a normal nipple; or a known area of fat necrosis, fibroadenoma, abscess, or other benign process. The use of a "probably benign" assessment on nuclear breast imaging is discouraged because the rate of malignancy approaches $5 \%$ for such findings (50), exceeding the accepted $2 \%$ threshold used in other breast imaging (55).

For ${ }^{99 \mathrm{~m}} \mathrm{Tc}$-sestamibi-based imaging, although a method of quantification with dual-head systems has been described (56), intensity of uptake is not routinely quantified with current software. Subcutaneous fat is used as the reference standard, with backgroundparenchyma uptake and lesion uptake described qualitatively as photopenic (less than subcutaneous fat), mild, moderate, or marked. Background uptake of ${ }^{99 \mathrm{~m}} \mathrm{Tc}$-sestamibi can be greater in the luteal phase of the menstrual cycle (57) and in postmenopausal women using hormonal replacement therapy (58) and tends to be greater in dense breasts $(57,58)$, although 72 of $164(44 \%)$ women with

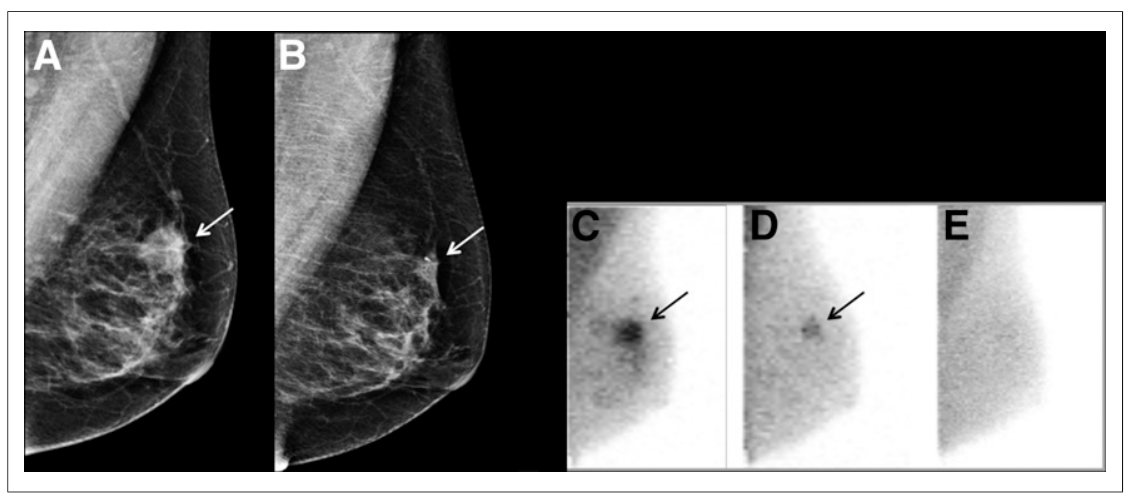

FIGURE 2. Monitoring response to primary chemotherapy with MBI. This 45-y-old woman presented with palpable lump in left breast. (A) Initial MLO mammogram shows irregular, dense 2.3-cm mass (arrow). Ultrasound-guided core biopsy showed grade 3 IDC, weakly positive for estrogen and progesterone receptors ( $<5 \%$ each) and HER2-negative. Patient began primary chemotherapy. (B) Follow-up mammogram at completion of primary chemotherapy shows smaller mass with clip (arrow). It is uncertain from mammography how much of residual mass represents tumor vs. fibrosis. (C) Pretreatment MLO MBI image after intravenous injection of $300 \mathrm{MBq}(8 \mathrm{mCi})$ of ${ }^{99 \mathrm{mTc}} \mathrm{T}$-sestamibi shows intense uptake in irregular $2.5-\mathrm{cm}$ mass corresponding to known cancer (arrow), with patchy moderate background uptake. (D) Follow-up MLO MBI image after 4 cycles of chemotherapy shows reduction in size and intensity of uptake in tumor (arrow), compatible with partial treatment response. (E) Follow-up MLO MBI image at completion of chemotherapy (same day as mammogram in B), shows no detectable residual tumor, suggesting complete response. At histopathology 1 mo later, microscopic focus of high-nuclear-grade DCIS was found with no residual invasive tumor. Functional imaging with nuclear breast imaging can improve assessment of treatment response earlier and with greater confidence than anatomic imaging. (Courtesy of Carrie Hruska, PhD, Mayo Clinic.) 
extremely dense parenchyma showed photopenic background in the Mayo series (58). As with MRI, in which increased backgroundparenchyma enhancement in the contralateral breast is independently associated with breast cancer $(59,60)$, it is possible that increased background-parenchyma uptake of ${ }^{99 \mathrm{~m}} \mathrm{Tc}$-sestamibi could predict an increased risk of breast cancer, but further study is warranted.

On breast PET, uptake can be quantified by drawing a region of interest with comparison typically to a region of normal background parenchyma. Background-parenchyma uptake of ${ }^{18} \mathrm{~F}-\mathrm{FDG}$ increases with increasing breast density, with about a twofold average difference between extremely dense breasts and fatty breasts (61). In one series, the uptake ratios of tumor to normal tissue on PEM were higher than those seen on PET/CT for small tumors (9), but quantification is generally similar for PEM and PET/CT $(8,9)$ despite the lack of attenuation correction on PEM.

\section{TUMOR SUBTYPES}

ILC can be notoriously difficult to identify on mammography because it tends to grow in single-file columns of cells rather than forming a discrete mass or causing distortion, and calcifications are quite rare with ILC (62). ILC is generally seen well on ${ }^{99 m} \mathrm{Tc}-$ sestamibi-based breast imaging (63). Uptake is less intense in ILC than in invasive ductal carcinoma (IDC); and in one large MBI series (6) sensitivity to ILC foci, at 38 of $55(69 \%)$, was lower than that to IDC, at 210 of 227 (92.5\%; $P=0.0062)$. The sensitivity of ${ }^{99 m} \mathrm{Tc}-$ sestamibi-based imaging to DCIS is estimated at $60 \%-91 \%$ on the basis of small series (64) and unpublished results (Deborah Rhodes, written communication, 2014).

Quantitative uptake of ${ }^{18} \mathrm{~F}$-FDG is lower in ILC and DCIS than in IDC $(3,8)$. PEM sensitivity to newly detected DCIS foci has been found to be 23 of 56 (41\%) in women with cancer elsewhere who underwent mammography and MRI (10).

High-grade IDC is seen well on nuclear breast imaging. Quantitatively higher ${ }^{18} \mathrm{~F}$-FDG uptake has been observed with estrogen receptor-negative, HER2-receptor-positive tumors and triple-negative tumors than with estrogen receptor-positive disease (65-67). Higher ${ }^{18} \mathrm{~F}$-FDG uptake in the primary breast cancer is predictive of an increased risk of recurrence $(68)$.

\section{FUTURE}

For $\gamma$-camera breast imaging to be widely adopted for screening, at a minimum there should be proof that women receiving MBI have lower rates of clinically detected cancers in the interval between screenings (interval cancers) and lower rates of advanced-stage breast cancer than a control group not receiving MBI. Ideally, there also would not be increased rates of lowand intermediate-grade DCIS in the MBI group. Incidence screening results are unknown. Direct MBI-guided breast biopsy is needed so that MRI is not required to sort out abnormalities seen only on MBI; this process is under development and does exist for BSGI systems.

One area of great, but largely unrecognized, potential for nuclear breast imaging is in predicting and assessing response to primary (neoadjuvant) chemotherapy (Figs. 2 and 3). In a pilot study of 19 patients imaged sequentially with MBI, a decrease in the tumor-tobackground ratio 3-5 wk after the initial round of chemotherapy was shown to predict response to treatment; larger studies are in progress (69). Lack of a substantial decrease in ${ }^{18} \mathrm{~F}$-FDG uptake after 2 cycles of chemotherapy has been shown to predict residual

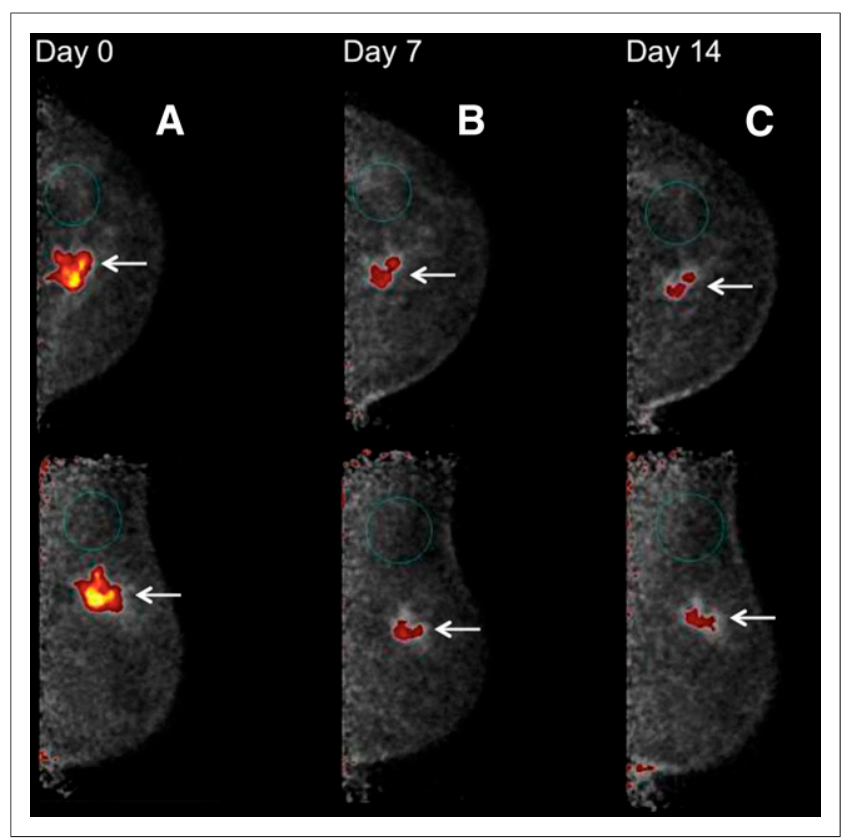

FIGURE 3. PEM response to primary chemotherapy. This 53-y-old woman presented with lump in left breast, corresponding to $4.3-\mathrm{cm}$ irregular mass on mammography (not shown). Ultrasound-guided core biopsy showed grade 3 IDC that was weakly estrogen receptor-positive $(<4 \%)$, progesterone receptor-negative, and HER2-positive, with axillary node metastasis. (A) Initial PEM craniocaudal (upper) and MLO (lower) 10-min images (day 0 ) obtained $1 \mathrm{~h}$ after intravenous injection of $370 \mathrm{MBq}$ $(10 \mathrm{mCi})$ of ${ }^{18} \mathrm{~F}-\mathrm{FDG}$ show intense uptake in irregular mass corresponding to known cancer (arrows), with tumor-to-normal tissue ratio of 13.8. (B) Seven days after first chemotherapy treatment with docetaxel, carboplatin, and trastuzumab, PEM study was repeated using $370 \mathrm{MBq}(10 \mathrm{mCi})$ of ${ }^{18} \mathrm{~F}-\mathrm{FDG}$, showing smaller mass (arrows) with less intense uptake and tumor-to-normal tissue ratio of 5.9. (C) Fourteen days after first chemotherapy treatment, PEM study was repeated again using $370 \mathrm{MBq}(10 \mathrm{mCi})$ of ${ }^{18} \mathrm{~F}-\mathrm{FDG}$, showing further reduction in size of tumor mass (arrows) and in intensity of uptake and tumor-to-normal tissue ratio of 4.5. At completion of treatment, lumpectomy showed residual $0.8-\mathrm{cm}$ cancer and 1 of 10 axillary nodes were metastatic, consistent with partial treatment response. Response to treatment within $7 \mathrm{~d}$ shown on PEM is predictive of overall response. (Courtesy of Mary K. Hayes, MD, Memorial Healthcare System.)

tumor at the conclusion of chemotherapy and a high risk of recurrence for triple-negative breast cancer (70).

Promising work is ongoing with many other radiotracers not currently approved for clinical use in the United States, including ${ }^{99 \mathrm{~m}} \mathrm{Tc}$-tetrofosmin $(71,72)$ and a ${ }^{99 \mathrm{~m}} \mathrm{Tc}$-labeled angiogenesis agent (NC100692, a peptide that binds to receptors of the integrin class) (73). ${ }^{18} \mathrm{~F}$-fluoroestradiol binds to estrogen receptors and is being explored for characterization of metastatic lesions outside the liver in women with estrogen receptor-positive breast cancer (74); ${ }^{18} \mathrm{~F}$-fluoroestradiol may have a role in predicting early response to treatment in the breast, with initial flare in responders (75). $3^{\prime}$-deoxy-3'-18 F-fluorothymidine ( $\left.{ }^{18} \mathrm{~F}-\mathrm{FLT}\right)$ is an analog of thymidine that is phosphorylated by thymidine kinase, the activity of which is increased in rapidly dividing cells. ${ }^{18} \mathrm{~F}-\mathrm{FLT}$ cannot be incorporated into DNA but rather is trapped in the cytoplasm. ${ }^{18}$ F-FLT shows high liver and bone uptake but low brain uptake and can be used to assess for brain metastases. Use of ${ }^{18} \mathrm{~F}$-FLT in early studies assessing treatment response has been reviewed by Kong et al. (76). 


\section{SUMMARY}

Standardized technique and interpretive criteria are in place for ${ }^{99} \mathrm{~m}$ Tc-sestamibi- and ${ }^{18} \mathrm{~F}-\mathrm{FDG}$-based dedicated breast imaging. Evidence from women with cancer and screening studies to date suggests that ${ }^{99 \mathrm{~m}} \mathrm{Tc}$-sestamibi-based breast imaging using dedicated dual-head detector systems has sensitivity comparable to that of MRI but higher specificity. Results to date may be biased by the lack of direct MBI-guided biopsy and the resulting need for MRI of equivocal findings. Importantly, direct stereotactic biopsy is available for BSGI. Efforts are ongoing to reduce radiotracer dose and time to complete imaging, but ${ }^{99 \mathrm{~m} T c-s e s t a m i b i-b a s e d ~ i m a g i n g ~ h a s ~}$ been shown to be cost-effective for screening.

Breast PET also shows comparable sensitivity to MRI but higher specificity, and direct PEM-guided biopsy is available. Both ${ }^{99 \mathrm{~m} T c-}$ sestamibi- and ${ }^{18}$ F-FDG-based breast imaging benefit from the patient fasting and sitting in warm conditions after the injection of a radiotracer, but ${ }^{99 \mathrm{~m}} \mathrm{Tc}$-sestamibi imaging can begin essentially immediately after injection, whereas breast PET requires a minimum of a 1-h circulation time. PET tracers are high-energy and require substantial shielding. Breast PET can be used in assessing the local extent of breast cancer, and single-center results show some benefit from ${ }^{99 \mathrm{~m}} \mathrm{Tc}$-sestamibi-based imaging, but neither has been shown to reduce positive margins or recurrence; further study is needed. Both methods show promise in assessing the response to primary chemotherapy. Comparison of both methods with contrast-enhanced mammography $(77,78)$ is needed.

Importantly, although specificity appears favorable with nuclear breast imaging, false-positives are not uncommon and can include fat necrosis, fibroadenomas, papillomas, normal lymph nodes, abscesses, phyllodes tumors, lobular carcinoma in situ, atypical ductal hyperplasia, and sometimes even fibrocystic change $(61,79)$. Therefore, it is important to correlate findings with mammography, other breast imaging, and prior biopsy history and therefore to include breast imaging specialists in interpreting nuclear breast imaging studies. Percutaneous biopsy should be performed of any suspicious findings on nuclear breast imaging that would change patient management, and a "probably benign" assessment should be avoided because of a malignancy rate exceeding $2 \%$.

\section{DISCLOSURE}

No potential conflict of interest relevant to this article was reported.

\section{ACKNOWLEDGMENTS}

I thank Carrie Hruska, $\mathrm{PhD}$, Michael O'Connor, $\mathrm{PhD}$, and the rest of Team Mayo at the Mayo Clinic for many helpful discussions, images, and comments regarding MBI. I also thank Mary K. Hayes, MD, for supplying PEM images.

\section{REFERENCES}

1. Baldwin JA, Bag AK, White SL, Palot-Manzil FF, O'Malley JP. All you need to know as an authorized user. AJR. 2015;205:251-258.

2. Khalkhali I, Villanueva-Meyer J, Edell SL, et al. Diagnostic accuracy of ${ }^{99 \mathrm{~m} T c-}$ sestamibi breast imaging: multicenter trial results. J Nucl Med. 2000;41:1973-1979.

3. Avril N, Rose CA, Schelling M, et al. Breast imaging with positron emission tomography and fluorine-18 fluorodeoxyglucose: use and limitations. J Clin Oncol. 2000;18:3495-3502.

4. Tadwalkar RV, Rapelyea JA, Torrente J, et al. Breast-specific gamma imaging as an adjunct modality for the diagnosis of invasive breast cancer with correlation to tumour size and grade. Br J Radiol. 2012;85:e212-e216.
5. Hruska CB, Boughey JC, Phillips SW, et al. Scientific Impact Recognition Award: molecular breast imaging - a review of the Mayo Clinic experience. Am J Surg. 2008;196:470-476.

6. Conners AL, Jones KN, Hruska CB, Geske JR, Boughey JC, Rhodes DJ. Directconversion molecular breast imaging of invasive breast cancer: imaging features, extent of invasive disease, and comparison between invasive ductal and lobular histology. AJR. 2015;205:W374-W381.

7. Hruska CB, Rhodes DJ, Collins DA, Tortorelli CL, Askew JW, O'Connor MK. Evaluation of molecular breast imaging in women undergoing myocardial perfusion imaging with ${ }^{99 m}$ Tc-sestamibi. $J$ Womens Health (Larchmt). 2012;21:730-738.

8. Kalinyak JE, Berg WA, Schilling K, Madsen KS, Narayanan D, Tartar M. Breast cancer detection using high-resolution breast PET compared to whole-body PET or PET/CT. Eur J Nucl Med Mol Imaging. 2014;41:260-275.

9. Eo JS, Chun IK, Paeng JC, et al. Imaging sensitivity of dedicated positron emission mammography in relation to tumor size. Breast. 2012;21:66-71.

10. Berg WA, Madsen KS, Schilling K, et al. Breast cancer: comparative effectiveness of positron emission mammography and MR imaging in presurgical planning for the ipsilateral breast. Radiology. 2011;258:59-72.

11. O'Connor MK, Hruska CB, Tran TD, et al. Factors influencing the uptake of ${ }^{99 \mathrm{~m}} \mathrm{Tc}$-sestamibi in breast tissue on molecular breast imaging. J Nucl Med Technol. 2015;43:13-20.

12. Hruska CB, Weinmann AL, Tello Skjerseth CM, et al. Proof of concept for lowdose molecular breast imaging with a dual-head CZT gamma camera: part IIevaluation in patients. Med Phys. 2012;39:3476-3483.

13. Mettler FAJ, Huda W, Yoshizumi TT, Mahesh M. Effective doses in radiology and diagnostic nuclear medicine: a catalog. Radiology. 2008;248:254-263.

14. Swanson TN, Troung DT, Paulsen A, Hruska CB, O'Connor MK. Adsorption of ${ }^{99 \mathrm{~m}} \mathrm{Tc}$-sestamibi onto plastic syringes: evaluation of factors affecting the degree of adsorption and their impact on clinical studies. J Nucl Med Technol. 2013;41: 247-252.

15. Hendrick RE. Radiation doses and cancer risks from breast imaging studies. Radiology. 2010;257:246-253.

16. AAPM position statement on radiation risks from medical imaging procedures. American Association of Physicists in Medicine website. http://www.aapm.org/ org $/$ policies $/$ details.asp id $=318 \&$ type $=P P \&$ current $=$ true. Published December 13, 2011. Accessed November 17, 2015.

17. Weigert JM, Bertrand ML, Lanzkowsky L, Stern LH, Kieper DA. Results of a multicenter patient registry to determine the clinical impact of breast-specific gamma imaging: a molecular breast imaging technique. AJR. 2012;198:W69-W75.

18. Brem RF, Floerke AC, Rapelyea JA, Teal C, Kelly T, Mathur V. Breast-specific gamma imaging as an adjunct imaging modality for the diagnosis of breast cancer. Radiology. 2008;247:651-657.

19. Wahner-Roedler DL, Hruska CB, O'Connor MK, et al. Molecular breast imaging for women presenting with a history of nonreproducible bloody nipple discharge and negative findings on routine imaging studies: a pilot study. $J$ Surg Radiol. 2011;2:92-99.

20. Houssami N, Ciatto S, Macaskill P, et al. Accuracy and surgical impact of magnetic resonance imaging in breast cancer staging: systematic review and meta-analysis in detection of multifocal and multicentric cancer. J Clin Oncol. 2008;26:3248-3258.

21. Brennan ME, Houssami N, Lord S, et al. Magnetic resonance imaging screening of the contralateral breast in women with newly diagnosed breast cancer: systematic review and meta-analysis of incremental cancer detection and impact on surgical management. J Clin Oncol. 2009;27:5640-5649.

22. Brem RF, Shahan C, Rapelyea JA, et al. Detection of occult foci of breast cancer using breast-specific gamma imaging in women with one mammographic or clinically suspicious breast lesion. Acad Radiol. 2010;17:735-743.

23. Zhou M, Johnson N, Gruner S, et al. Clinical utility of breast-specific gamma imaging for evaluating disease extent in the newly diagnosed breast cancer patient. Am J Surg. 2009;197:159-163.

24. Killelea BK, Gillego A, Kirstein LJ, et al. George Peters Award: how does breast-specific gamma imaging affect the management of patients with newly diagnosed breast cancer? Am J Surg. 2009;198:470-474.

25. Kim BS. Usefulness of breast-specific gamma imaging as an adjunct modality in breast cancer patients with dense breast: a comparative study with MRI. Ann Nucl Med. 2012;26:131-137.

26. Edwards C, Williams S, McSwain AP, et al. Breast-specific gamma imaging influences surgical management in patients with breast cancer. Breast J. 2013;19:512-519.

27. Berg WA, Madsen KS, Schilling K, et al. Comparative effectiveness of positron emission mammography and MRI in the contralateral breast of women with newly diagnosed breast cancer. AJR. 2012;198:219-232

28. Houssami N, Turner R, Macaskill P, et al. An individual person data metaanalysis of preoperative magnetic resonance imaging and breast cancer recurrence. J Clin Oncol. 2014;32:392-401. 
29. Bae MS, Moon HG, Han W, et al. Early stage triple-negative breast cancer: imaging and clinical-pathologic factors associated with recurrence. Radiology. July 31, 2015 [Epub ahead of print].

30. Solin LJ, Orel SG, Hwang WT, Harris EE, Schnall MD. Relationship of breast magnetic resonance imaging to outcome after breast-conservation treatment with radiation for women with early-stage invasive breast carcinoma or ductal carcinoma in situ. J Clin Oncol. 2008;26:386-391.

31. Turnbull L, Brown S, Harvey I, et al. Comparative effectiveness of MRI in breast cancer (COMICE) trial: a randomised controlled trial. Lancet. 2010;375:563-571.

32. Peters NH, van Esser S, van den Bosch MA, et al. Preoperative MRI and surgical management in patients with nonpalpable breast cancer: the MONET-randomised controlled trial. Eur J Cancer. 2011;47:879-886.

33. Mann RM, Loo CE, Wobbes T, et al. The impact of preoperative breast MRI on the re-excision rate in invasive lobular carcinoma of the breast. Breast Cancer Res Treat. 2010;119:415-422.

34. Rodenko GN, Harms SE, Pruneda JM, et al. MR imaging in the management before surgery of lobular carcinoma of the breast: correlation with pathology. AJR. 1996;167:1415-1419.

35. Werner J, Rapelyea JA, Yost KG, Brem RF. Quantification of radio-tracer uptake in axillary lymph nodes using breast specific gamma imaging (BSGI): benign radio-tracer extravasation versus uptake secondary to breast cancer. Breast J. 2009;15:579-582.

36. Pan L, Han Y, Sun X, Liu J, Gang H. FDG-PET and other imaging modalities for the evaluation of breast cancer recurrence and metastases: a meta-analysis. $J$ Cancer Res Clin Oncol. 2010;136:1007-1022.

37. Nelson HD, Tyne K, Naik A, Bougatsos C, Chan BK, Humphrey L. Screening for breast cancer: an update for the U.S. Preventive Services Task Force. Ann Intern Med. 2009;151:727-737, W237-W242.

38. Saslow D, Boetes C, Burke W, et al. American Cancer Society guidelines for breast screening with MRI as an adjunct to mammography. CA Cancer J Clin. 2007;57:75-89.

39. Harvey JA, Bovbjerg VE. Quantitative assessment of mammographic breast density: relationship with breast cancer risk. Radiology. 2004;230:29-41.

40. Kerlikowske K, Zhu W, Hubbard RA, et al. Outcomes of screening mammography by frequency, breast density, and postmenopausal hormone therapy. JAMA Intern Med. 2013;173:807-816.

41. Rechtman LR, Lenihan MJ, Lieberman JH, et al. Breast-specific gamma imaging for the detection of breast cancer in dense versus nondense breasts. AJR. 2014; 202:293-298.

42. Legislation and regulations: what is required? DenseBreast-info website. http:// densebreast-info.org/legisiation.aspx. Revised September 15, 2015. Accessed November 17, 2015.

43. Sickles EA, D'Orsi CJ, Bassett LW, et al. ACR BI-RADS mammography. In: ACR BI-RADS Atlas, Breast Imaging Reporting and Data System. Reston, VA: American College of Radiology; 2013.

44. Brem RF, Rapelyea JA, Zisman G, et al. Occult breast cancer: scintimammography with high-resolution breast-specific gamma camera in women at high risk for breast cancer. Radiology. 2005;237:274-280.

45. Rhodes DJ, Hruska CB, Conners AL, et al. Journal club: molecular breast imaging at reduced radiation dose for supplemental screening in mammographically dense breasts. AJR. 2015;204:241-251.

46. Rhodes DJ, Hruska CB, Phillips SW, Whaley DH, O'Connor MK. Dedicated dual-head gamma imaging for breast cancer screening in women with mammographically dense breasts. Radiology. 2011;258:106-118.

47. Hruska CB, Conners AL, Jones KN, et al. Diagnostic workup and costs of a single supplemental molecular breast imaging screen of mammographically dense breasts. AJR. 2015;204:1345-1353.

48. Kalinyak JE, Schilling K, Berg WA, et al. PET-guided breast biopsy. Breast J. 2011;17:143-151.

49. Conners AL, Maxwell RW, Tortorelli CL, et al. Gamma camera breast imaging lexicon. AJR. 2012;199:W767-W774.

50. Narayanan D, Madsen KS, Kalinyak JE, Berg WA. Interpretation of positron emission mammography: feature analysis and rates of malignancy. AJR. 2011;196:956-970.

51. Conners AL, Hruska CB, Tortorelli CL, et al. Lexicon for standardized interpretation of gamma camera molecular breast imaging: observer agreement and diagnostic accuracy. Eur J Nucl Med Mol Imaging. 2012;39:971-982.

52. Narayanan D, Madsen KS, Kalinyak JE, Berg WA. Interpretation of positron emission mammography and MRI by experienced breast imaging radiologists: performance and observer reproducibility. AJR. 2011;196:971-981.

53. Mendelson EB, Böhm-Vélez M, Berg WA, et al. ACR BI-RADS ultrasound. In: ACR BI-RADS Atlas, Breast Imaging Reporting and Data System. Reston, VA: American College of Radiology; 2013.

54. Morris EA, Comstock CE, Lee C, et al. ACR BI-RADS magnetic resonance imaging. In: ACR BI-RADS Atlas, Breast Imaging Reporting and Data System. Reston, VA: American College of Radiology; 2013.
55. Sickles EA, D'Orsi CJ. Follow-up and outcome monitoring. In: ACR BI-RADS Atlas, Breast Imaging Reporting and Data System. Reston, VA: American College of Radiology; 2013.

56. Hruska CB, O'Connor MK. Quantification of lesion size, depth, and uptake using a dual-head molecular breast imaging system. Med Phys. 2008;35:1365-1376.

57. Hruska CB, Conners AL, Vachon CM, et al. Effect of menstrual cycle phase on background parenchymal uptake at molecular breast imaging. Acad Radiol. 2015; 22:1147-1156.

58. Hruska CB, Rhodes DJ, Conners AL, et al. Background parenchymal uptake during molecular breast imaging and associated clinical factors. AJR. 2015;204: W363-W370.

59. King V, Brooks JD, Bernstein JL, Reiner AS, Pike MC, Morris EA. Background parenchymal enhancement at breast MR imaging and breast cancer risk. Radiology. 2011;260:50-60.

60. Dontchos BN, Rahbar H, Partridge SC, et al. Are qualitative assessments of background parenchymal enhancement, amount of fibroglandular tissue on MR images, and mammographic density associated with breast cancer risk? Radiology. 2015;276:371-380.

61. Berg WA, Weinberg IN, Narayanan D, et al. High-resolution fluorodeoxyglucose positron emission tomography with compression ("positron emission mammography") is highly accurate in depicting primary breast cancer. Breast J. 2006;12:309-323.

62. Mendelson EB, Harris KM, Doshi N, Tobon H. Infiltrating lobular carcinoma: mammographic patterns with pathologic correlation. AJR. 1989;153:265-271.

63. Brem RF, Ioffe M, Rapelyea JA, et al. Invasive lobular carcinoma: detection with mammography, sonography, MRI, and breast-specific gamma imaging. AJR. 2009; 192:379-383.

64. Brem RF, Fishman M, Rapelyea JA. Detection of ductal carcinoma in situ with mammography, breast specific gamma imaging, and magnetic resonance imaging: a comparative study. Acad Radiol. 2007;14:945-950.

65. Kim BS, Sung SH. Usefulness of ${ }^{18}$ F-FDG uptake with clinicopathologic and immunohistochemical prognostic factors in breast cancer. Ann Nucl Med. 2012;26:175-183.

66. Groheux D, Giacchetti S, Moretti JL, et al. Correlation of high ${ }^{18} \mathrm{~F}$-FDG uptake to clinical, pathological and biological prognostic factors in breast cancer. Eur J Nucl Med Mol Imaging. 2011;38:426-435.

67. Garcia Vicente AM, Soriano Castrejon A, Leon Martin A, et al. Molecular subtypes of breast cancer: metabolic correlation with ${ }^{18}$ F-FDG PET/CT. Eur J Nucl Med Mol Imaging. 2013;40:1304-1311.

68. Oshida M, Uno K, Suzuki M, et al. Predicting the prognoses of breast carcinoma patients with positron emission tomography using 2-deoxy-2-fluoro- ${ }^{18} \mathrm{~F}-\mathrm{D}$-glucose. Cancer. 1998;82:2227-2234.

69. Mitchell D, Hruska CB, Boughey JC, et al. ${ }^{99 \mathrm{~m}}$ Tc-sestamibi using a direct conversion molecular breast imaging system to assess tumor response to neoadjuvant chemotherapy in women with locally advanced breast cancer. Clin Nucl Med. 2013;38:949-956.

70. Groheux D, Hindie E, Giacchetti S, et al. Triple-negative breast cancer: early assessment with ${ }^{18}$ F-FDG PET/CT during neoadjuvant chemotherapy identifies patients who are unlikely to achieve a pathologic complete response and are at a high risk of early relapse. J Nucl Med. 2012;53:249-254.

71. Schillaci O, Spanu A, Danieli R, Madeddu G. Molecular breast imaging with gamma emitters. Q J Nucl Med Mol Imaging. 2013;57:340-351.

72. Spanu A, Sanna D, Chessa F, Cottu P, Manca A, Madeddu G. Breast scintigraphy with breast-specific $\gamma$-camera in the detection of ductal carcinoma in situ: a correlation with mammography and histologic subtype. J Nucl Med. 2012;53:1528-1533.

73. Bach-Gansmo T, Bogsrud TV, Skretting A. Integrin scintimammography using a dedicated breast imaging, solid-state $\gamma$-camera and ${ }^{99 \mathrm{~m}} \mathrm{Tc}$-labelled NC100692. Clin Physiol Funct Imaging. 2008;28:235-239.

74. van Kruchten M, Glaudemans AW, de Vries EF, et al. PET imaging of estrogen receptors as a diagnostic tool for breast cancer patients presenting with a clinical dilemma. J Nucl Med. 2012;53:182-190.

75. Linden HM, Stekhova SA, Link JM, et al. Quantitative fluoroestradiol positron emission tomography imaging predicts response to endocrine treatment in breast cancer. J Clin Oncol. 2006;24:2793-2799.

76. Kong FL, Kim EE, Yang DJ. Targeted nuclear imaging of breast cancer: status of radiotracer development and clinical applications. Cancer Biother Radiopharm. 2012;27:105-112.

77. Jochelson MS, Dershaw DD, Sung JS, et al. Bilateral contrast-enhanced dualenergy digital mammography: feasibility and comparison with conventional digital mammography and MR imaging in women with known breast carcinoma. Radiology. 2013;266:743-751.

78. Lewin JM, Isaacs PK, Vance V, Larke FJ. Dual-energy contrast-enhanced digital subtraction mammography: feasibility. Radiology. 2003;229:261-268.

79. Ling CM, Coffey CM, Rapelyea JA, et al. Breast-specific gamma imaging in the detection of atypical ductal hyperplasia and lobular neoplasia. Acad Radiol. 2012; 19:661-666. 